SUPPORTING INFROMATION

\title{
Petroleum Size Exclusion Chromatography. Mechanisms Explaining the NMP front peak
}

Simon Ivar Andersen

Danish Hydrocarbon Research \& Technology Centre, Technical University of Denmark,

Bldg. 375, Kgs. Lyngby 2800, Denmark

Contents: Figures S1 to S5 and Table S1 


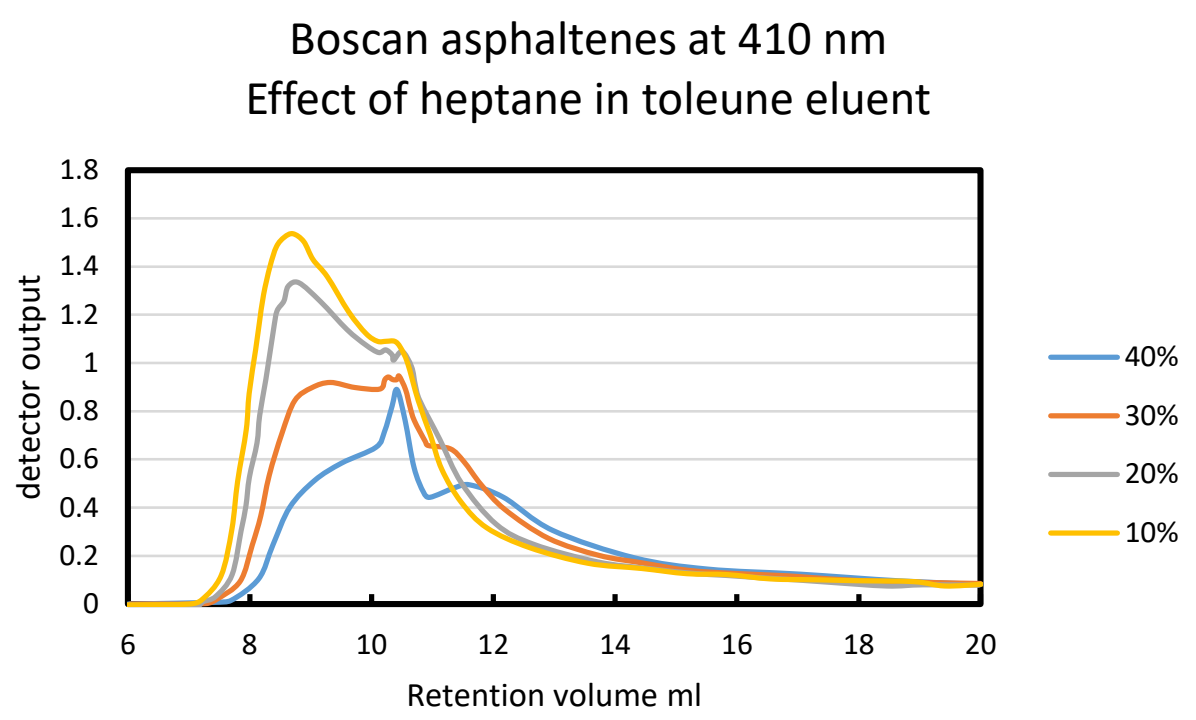

Figure S1. Similar to Figure 7 of the paper but expanded to 20 minutes or $20 \mathrm{ml}$ of eluent. This shows the dramatic effect of heptane addition to the toluene eluent, and how adsorption starts to dominate, and that the expected association is not leading to the presence of a peak at shorter retention time or volume. Notice that tailing is still present at 20 minutes but unaffected by the eluent composition. 
Wavelength effect on SEC

Boscan asphaltenes@2g/l in 40 \% C7/toluene

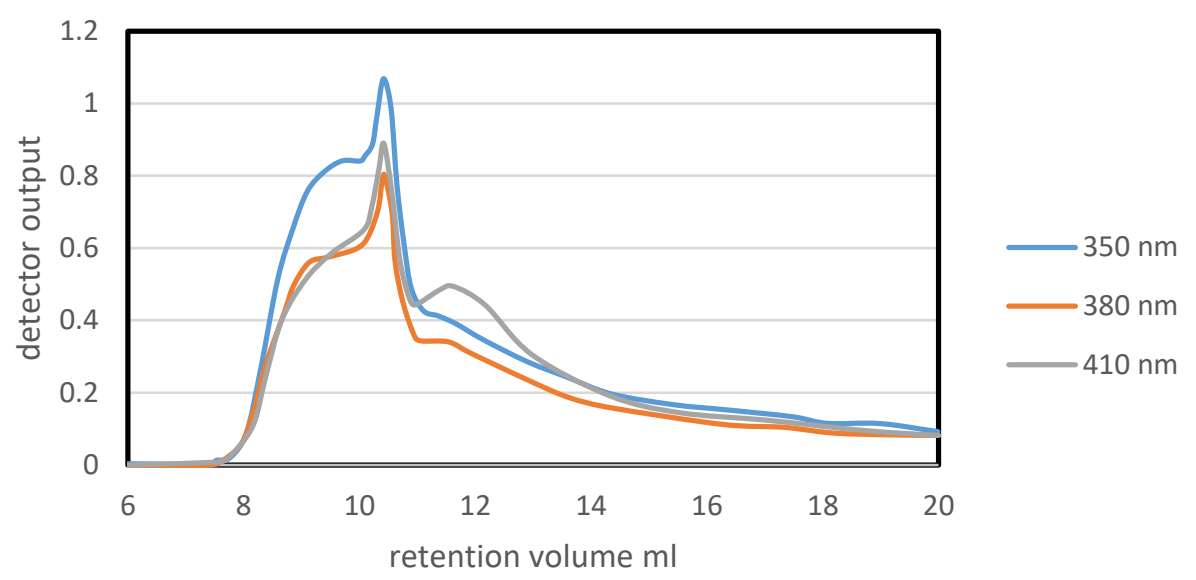

Figure S2. Effect of changing the detection wavelength on the SEC profile for the $40 \%$ heptane/toluene case. The peak at approx. 10.4 minutes has been related to small petroporphyrins.

Wavelength effect on SEC

Boscan asphaltenes @ 2g/l in $10 \%$ C7/toluene

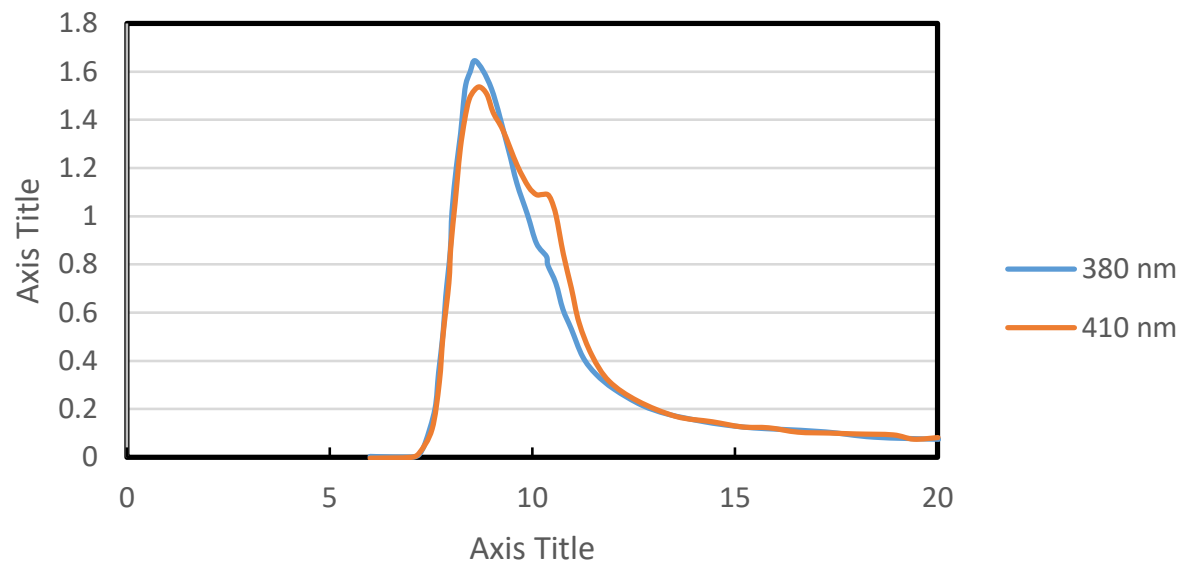

Figure S3. Effect of changing the detection wavelength on the SEC profile for the $10 \%$ heptane/toluene case. 
Boscan Asphaltenes in toluene. Effect of concentration on the SEC profile at $410 \mathrm{~nm}$.

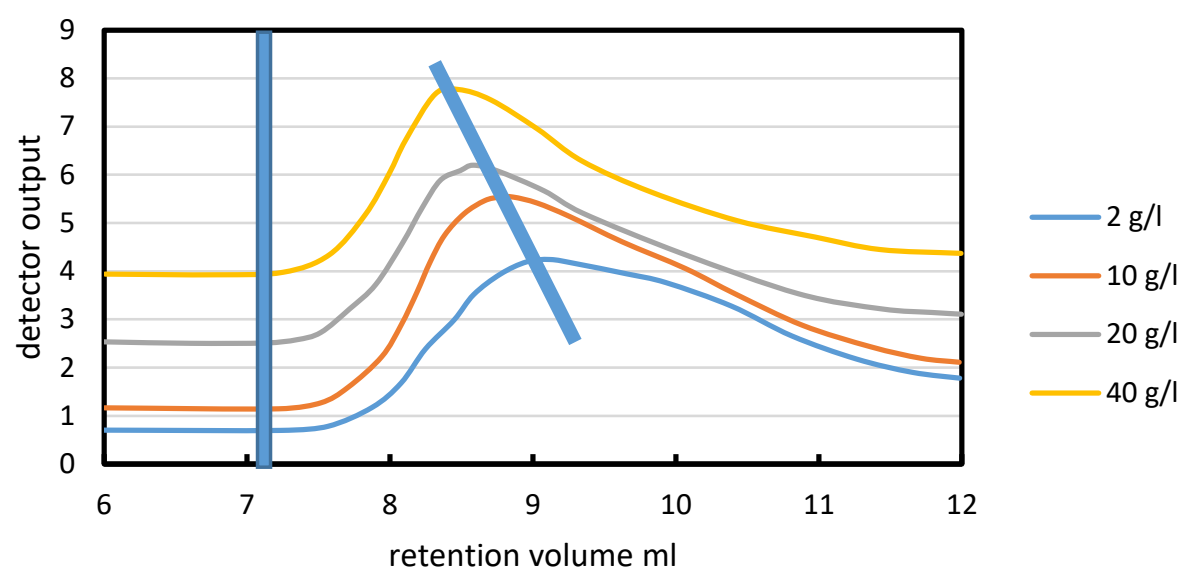

Figure S4. Effect of concentration on the SEC profile of Boscan asphaltenes. Notice the slight decrease of the initial point of departure and the quite significant change of the peak point as the concentration increase. 
Eluent Effect on Detector response @ 575 nm

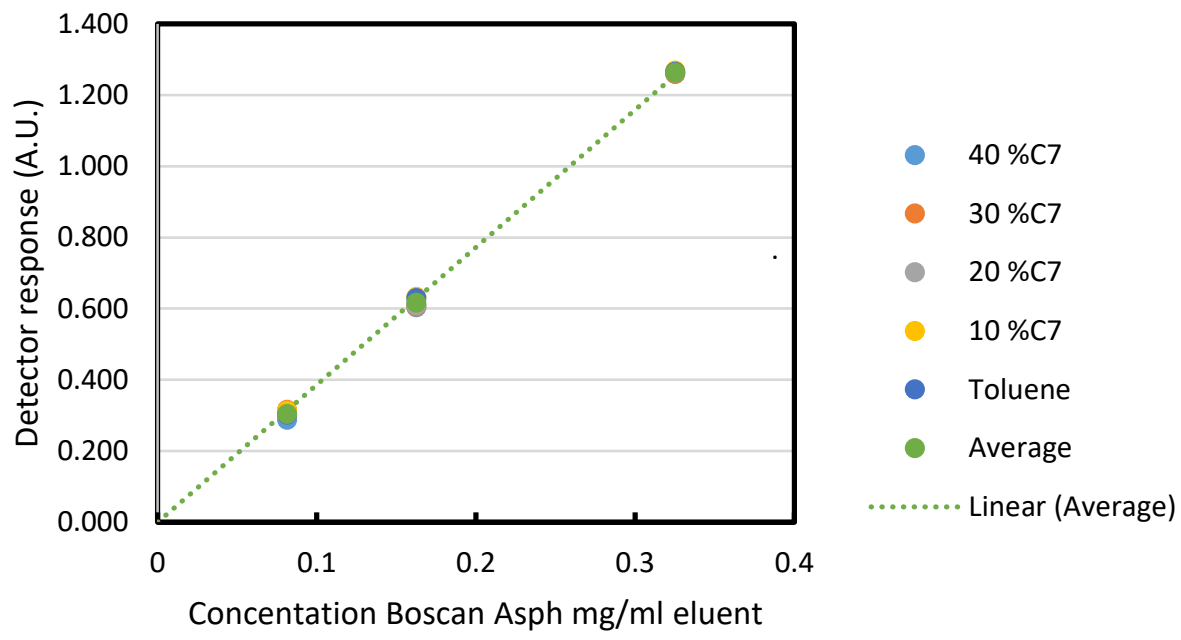

Figure S5. Test of the effect of solvent composition /heptane in toluene) on the detector response. As indicated in the table below there is overall a trend of a slightly higher detector response for pure toluene than for the $40 \% \mathrm{C} 7$ in toluene. However, the trend in between is overall not systematic. $575 \mathrm{~nm}$ was used due to the large response e.g. at $410 \mathrm{~nm}$ or lower used for the SEC.

\begin{tabular}{|c|c|c|c|c|}
\hline C7 & TOL & \multicolumn{2}{|c|}{$\begin{array}{c}\text { CONC BOSCAN } \\
\mathrm{mg} / \mathrm{ml}\end{array}$} & \multirow[b]{2}{*}{0.325} \\
\hline \multicolumn{2}{|c|}{ ELUENT } & 0.08125 & 0.1625 & \\
\hline $40 \% C 7$ & 60 & 0.29 & 0.60 & 1.26 \\
\hline 30 \%C7 & 70 & 0.32 & 0.61 & 1.26 \\
\hline $20 \% \mathrm{C7}$ & 80 & 0.30 & 0.61 & 1.26 \\
\hline $10 \% \mathrm{C7}$ & 90 & 0.31 & 0.63 & 1.27 \\
\hline \multirow[t]{4}{*}{ TOLUENE } & 100 & 0.30 & 0.63 & 1.27 \\
\hline & Average & 0.30 & 0.62 & 1.26 \\
\hline & STD.DEV. & 0.01 & 0.01 & 0.00 \\
\hline & $\%$ & 3.745106 & 2.20256 & 0.296867 \\
\hline
\end{tabular}

Table S1. Effect of eluent composition on detector response to asphaltene solution. The effect is significantly smaller compared to the changes in SEC profile reported in figure 7 of the main paper. 